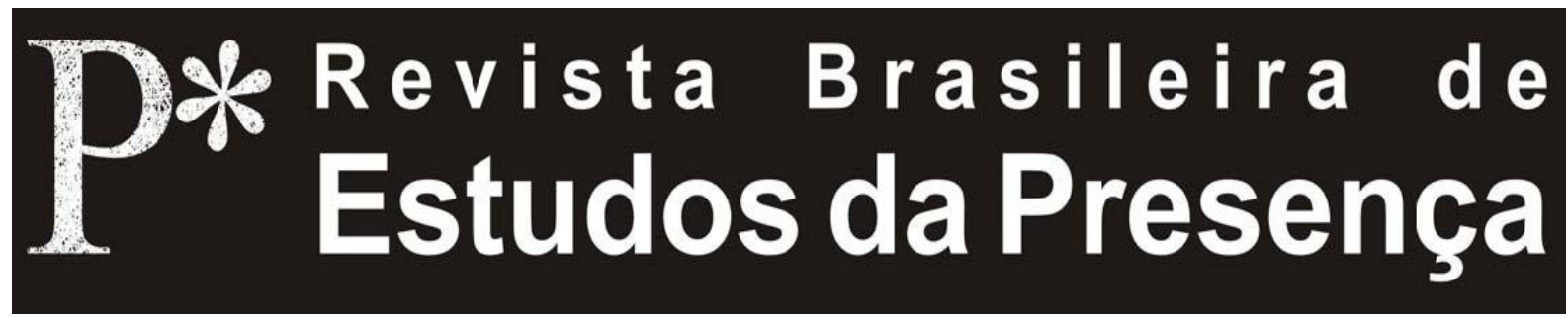

DOI - http://dx.doi.org/10.1590/2237-266036939

ISSN 2237-2660

\title{
Essência e Personalidade em Grotowski e Gurdjieff
}

Mauro Rodrigues

Universidade Federal de Minas Gerais - UFMG, Belo Horizonte, MG, Brasil

RESUMO - Essência e Personalidade em Grotowski e Gurdjieff - Este artigo estabelece relaçóes entre palavras de trabalho e conceitos em Grotowski e Gurdjieff. Particularmente, investiga os conceitos de essência e personalidade, comuns a Grotowski e Gurdjieff, relacionando-os com a presença e a qualidade da atenção, como emergência do contato voluntário entre esses dois aspectos. O contato voluntário implica condiçóes especiais, não naturais, mas artificiais, que podem ser criadas pelos seres humanos em sua interação recorrente e extraordinária.

Palavras-chave: Essência. Personalidade. Presença. Contato. Qualidade.

ABSTRACT - Essence and Personality in Grotowski and Gurdjieff - This article establishes relationships between working words and concepts in the work of Grotowski and Gurdjieff. Particularly, it investigates concepts of essence and personality, common to Grotowski and Gurdjieff, relating them to the presence and quality of attention, such as the emergency of voluntary contact between these two aspects. Voluntary contact implies special conditions which are not natural, but artificial, and which can be created by human beings in their recurring and extraordinary interactions.

Keywords: Essence. Personality. Presence. Contact. Quality.

RÉSUMÉ - L'Essence et la Personnalité de Grotowski et Gurdjieff - Cet article établit des relations entre les mots de travail et les concepts de Grotowski et Gurdjieff. Il explore en particulier les concepts d'essence et de personnalité communs à Grotowski et Gurdieff en les mettant en rapport avec la présence et la qualité d'attention, comme l'émergence do contact volontaire entre ces deux aspects. Ce contact volontaire requiert des conditions particulières, non naturelles mais artificielles, qui peuvent être créées par les êtres humains au cours de leur processus d'interaction récurrent et extraordinaire.

Mots-clés: Essence. Personnalité. Présence. Qualité. Contact. 
O surgimento da linguagem remonta a um período imemorial e mítico. Aceitar o outro como legítimo outro na convivência seria a condição primeira para tal surgimento, segundo Maturana, e só poderia ter ocorrido na cooperação, ainda que a linguagem eventualmente possa ser utilizada para a agressáo (Maturana, 2005). Uma civilização que tenha se desenvolvido na cooperação e nos legado a linguagem poderia ter um profundo conhecimento e compreensão do humano e da razão de ser e estar no mundo. De fato, é possível intuir a existência de tal conhecimento no contato com religióes e filosofias muito antigas, ainda que sua compreensão não se abra plenamente e permaneça um mistério, algo insondável. A busca dessa qualidade de conhecimento tem sido o foco de muitos pesquisadores em diversas áreas. Se por um lado tal investigaçáo aponta para o que nos é legado pela cultura, aponta também para um contato com uma natureza mais íntima e profunda dos impulsos humanos.

Esse parece ter sido um tema de fundo para o trabalho de Grotowski nas artes cênicas ${ }^{1}$, assim como de Gurdjieff em um campo amplo e de difícil definição. Além das diferenças nos objetivos e na forma como cada um conduziu seu trabalho, é possível identificar e até descrever alguns processos semelhantes em suas açôes. Eles não foram contemporâneos, porém, de fato, chegaram a usar palavras iguais para conceitos e experiências bastante próximas, ainda que náo tivessem a oportunidade de um contato presencial. Muito além das fronteiras de uma área específica da arte ou do conhecimento, o que parece tê-los movido foi uma inquietação de pesquisadores frente à complexidade do fenômeno humano e de suas possibilidades, onde o ofício aprendido poderia funcionar como um fino instrumento de contato e ação, um meio e não um fim, a arte como veículo. Este texto tratará de apontar algumas semelhanças e coincidências entre palavras e conceitos na esperança de que dessa comparação possa abrir-se ou ampliar-se uma compreensão do legado destes pesquisadores. Duas palavras seráo especialmente focadas, essência e personalidade. Elas representam aspectos centrais no corpo das ideias em Gurdjieff. Em Grotowski, ainda que elas não sejam frequentemente citadas nos textos, sua semelhança é assumida e notável em diversas passagens. Peter Brook aparece como um comentarista de Grotowski. Sendo um dos responsáveis pelo legado de Gurdjieff, parece também ter sido uma espécie de ponte entre Grotowski e Gurdjieff, ainda que estes últimos não tenham se encontrado presencialmente. 


\section{Gurdjieff (1866 -1949) e Grotowski (1933-1999)}

George Ivanovich Gurdjieff ${ }^{2}$ passou sua infância na fronteira da Ásia Menor (Ouspensky, 1989), recebendo impressóes de um lugar que estava entre o ocidente e o oriente. Desde cedo desenvolveu grande interesse por questóes fundamentais como a razáo da existência humana e dedicou sua vida a esclarecer tais questóes, empreendendo diversas viagens a locais onde intuía encontrar as respostas. Constituiu assim um corpo amplo de ideias e práticas que abarcam diversos domínios. Essas ideias ele nunca pretendeu tê-las criado, mas organizado e desenvolvido em uma forma compreensível e operante para a mente ocidental. Trata-se de um repertório de conhecimentos muito antigos colhidos em distintas tradiçóes como sufismo, cristianismo primitivo e budismo, que ele teve contato em visitas de pesquisa a regióes da Ásia e do Extremo Oriente. A natureza desses conhecimentos o levou a organizar um ambicioso projeto focado no trabalho sobre si, assim como no trabalho em grupo. Faria parte de seu propósito apresentar esse material de uma forma tal que fosse transformador na prática cotidiana.

Entre os anos de 1912 e 1949, quando faleceu, Gurdjieff trabalhou intensamente com seus alunos, primeiramente na Rússia e, em 1922, devido às condiçóes adversas criadas pela revolução bolchevista e pela primeira guerra mundial, fixou-se na França onde fundou o Instituto para o Desenvolvimento Harmonioso do Homem abrindo, posteriormente seçôes nos Estados Unidos da América ${ }^{3}$.

O trabalho de Gurdjieff é eminentemente prático e sua transmissão essencialmente oral. Contudo, ele deixou registros das ideias e de algumas práticas na forma de textos, de movimentos e de música. Alguns textos e a música estão atualmente publicados e para esses o acesso é irrestrito. Os movimentos são basicamente uma espécie de exercícios físicos que têm o intento de alinhar organicamente o corpo, o coração e a cabeça. Sáo praticados apenas no âmbito do Instituto, apoiados pelas condiçóes de trabalho aí criadas. Trechos desses movimentos aparecem no filme de Peter Brook, Encontros com Homens Notáveis, que é uma adaptação do livro homônimo escrito por Gurdjieff.

Tendo estudado o método das ações físicas de Stanislavski, Grotowski levou o trabalho sobre si do ator às últimas consequências na busca da organicidade. Esta trilha o conduziu, partindo da arte 
como espetáculo, em direção à arte como veículo. Grotowski desenvolveu um intenso trabalho com os seus atores nas diversas fases por que passou. Na última fase, cunhada por Peter Brook Arte como Veículo, em seu momento mais radical a audiência foi abolida, concentrando-se especificamente no trabalho atoral e nas possibilidades de interação e descobertas do grupo. Durante esse período também foram realizados encontros esporádicos com outros grupos e pesquisadores. Contudo, esta rápida descrição talvez seja uma abordagem um pouco horizontal de sua pesquisa e seu legado, correspondendo a uma visão panorâmica. Grotowski deixou pistas em seus textos, no entanto, sobre o processo transformador no qual ele e seus atores e colaboradores estavam envolvidos, a verticalidade desse processo não se poderia revelar a náo ser na prática, na experiência vivida e, assim, assemelhar-se-ia a uma forma de tradição oral. Atualmente, seu legado segue ainda exercendo grande influência através do trabalho desenvolvido por seus herdeiros Thomas Richards e Mario Biagini, no Workcenter, em Pontedera, na Itália.

Grotowski não teve contato direto com Gurdjieff e/ou seu trabalho. As informaçóes que obteve foram de caráter livresco, como ele mesmo afirma. No entanto, é notável a afinidade de suas ideias e até certa medida a prática em seus respectivos percursos. Um dos aspectos comuns aos dois é que além de uma pesquisa profunda em diversas tradiçóes, às vezes muito antigas tanto no ocidente quanto no oriente, o que os interessava era o que funcionava nessas tradiçóes, não no sentido de preservar a sua forma, mas o seu funcionamento. Assim, eles desenvolveram uma aplicação prática e justa desse material nas condiçôes atuais de seu trabalho fazendo desse modo uma conexão entre a tradição e a contemporaneidade. A relação com a tradição assume uma característica não dogmática, onde a pergunta tem um papel fundamental. Comentando as ideias e a leitura dos textos relativos à Gurdjieff, Grotowski afirma:

[...] desde o momento em que comecei a ler sobre o trabalho de Gurdjieff, as comparaçóes não somente deviam corroborar-se senão que deviam ademais tocar-me, é evidente. Resultar-me-ia difícil analisar: que detalhes, que elementos? Porque também pode resultar perigoso perguntarse: de onde vem um elemento, e de onde vem outro? $\mathrm{O}$ importante não é que venham de alguma parte, senão que funcionem. Está claro o critério? Isso quer dizer: há um elemento que funciona e se corrobora aqui e acolá. No caso de Gurdjieff, o impacto é de algo a uma vez muito antigo 
e contemporâneo. É impactante encontrar no mesmo trabalho a tradição e a busca (pesquisa), e ao mesmo tempo uma maneira de colocar certas perguntas fundamentais ${ }^{4}$ (Grotowski, 1997, p. 124-125).

O conhecimento que estes homens recolheram e desenvolveram tem um caráter eminentemente prático na medida em que se refere a experiências vividas, não obstante estar também oferecido em forma de ideias acessíveis através dos textos e de outros registros que deixaram. Mesmo sem uma conexão direta, arrisco afirmar que eles tiveram interesses e fontes comuns. Há um parentesco entre alguns termos de Grotowski e Gurdjieff. Há nos dois homens uma profunda conexão com conhecimentos e tradiçóes muito antigas, nem sempre em sua forma, mas principalmente em seu conteúdo transformador. Esta semelhança, Grotowski comenta da seguinte maneira:

Quando tive em mãos certos materiais, comprovei, com efeito, uma utilização similar de certos termos como, por exemplo, "mecanicidade", "associaçôes". Em outras partes, os termos diferem, porém, sem dúvida estão lá "máscara social", a "personalidade"... e, se poderia seguir e seguir! $\mathrm{O}$ que provavelmente seja mais importante mencionar é a complexidade da natureza humana, que abarca o corpo, e a interioridade - talvez com algo mais que realizar ou fazer - em direção ao que chamo hoje de "verticalidade" (Grotowski, 1997, p. 117).

A utilização similar de certos termos diz respeito a processos comuns que eles encontraram e que estáo relacionados ao ofício de ator e à organicidade da ação, assumindo a perspectiva de Grotowski como homem de teatro, mas que corresponderiam, na perspectiva do trabalho de Gurdjieff, à possibilidade de colocar o conhecido a serviço de uma busca pelo desconhecido. Segundo Gurdjieff, no mundo o conhecimento das coisas pode ser abordado de formas diferentes. Coisas que se pode conhecer tendo o corpo como principal articulador ou centro de conhecimento, outras podem ser conhecidas com um acento emocional e outras ainda com um acento mais mental. Isso varia de pessoa para pessoa e até de evento para evento, constituindo uma camada de subjetividade. O conhecimento através de uma dessas partes seria sempre, para o homem, um conhecimento parcial do evento que se conhece. Segundo Gurdjieff, seria necessária uma abordagem das três partes para constituir um conhecimento mais completo. Ouspensky, citando uma fala de Gurdjieff, escreve ${ }^{6}$ : 
[...] devemos compreender que cada função psíquica normal é um meio ou instrumento de conhecimento. Com o auxílio da mente, vemos um aspecto das coisas e dos acontecimentos, com o auxílio das emoçóes outro aspecto, com o auxílio das sensaçóes outro aspecto. $\mathrm{O}$ conhecimento mais completo que possamos ter de um assunto dado só pode ser obtido se o examinarmos simultaneamente através de nossos pensamentos, nossos sentimentos e nossas sensações (Ouspensky, 1989, p. 130).

Ocorre que o conhecimento que uma função pode aportar de um evento, quando sua operação é solitária e mecânica, pode tornarse um impedimento para que outra função também atue, na medida em que se aceita o evento como conhecido.

Grotowski sugere a incompletude do ser humano quando se refere a algo mais que realizar ou fazer. Esse é também um ponto comum entre eles. Para Gurdjieff os homens são seres cuja plena realização, a consumação de todas as suas potencialidades é também algo que está por ser feito e não poderia ocorrer mecanicamente. Segundo ele, a mecanicidade das açóes humanas é o que justamente se opóe a tal realização e para escapar a essa mecanicidade seria preciso primeiro vê-la, ser testemunha de sua ação. Do contrário, as reaçôes puramente mecânicas, que segundo Gurdjieff constituem certa camada de existência no homem, agiriam por ele como que saltando em sua frente impedindo-o de realmente fazer. Segundo Gurdjieff, nessas condições um homem não é um, mas vários que reagem às situaçóes de maneira absolutamente mecânica. Ouspensky, reconstituindo uma fala de Gurdjieff, escreve:

O homem não tem um "Eu" individual. Em seu lugar há centenas e milhares de pequenos "eus" separados, que a maior parte das vezes se ignoram, não mantém nenhuma relação ou, ao contrário, são hostis uns aos outros, exclusivos e incompatíveis. A cada minuto, a cada momento o homem diz ou pensa "eu". E a cada vez seu "eu" é diferente. Num instante era um pensamento, agora é um desejo, depois uma sensação, logo após outro pensamento e assim por diante, sem fim. O homem é uma pluralidade. O seu nome é legião (Ouspensky, 1989, p. 78).

Portanto, é possível vislumbrar a luta que se passaria no atuante frente a uma ação como a que propunha Grotowski. Ele não poderia estar sujeito a essa instabilidade que acomete o homem no cotidiano ordinário, sua mecanicidade, e para tanto deveria trabalhar sobre si seguindo de maneira precisa uma partitura de açóes, algo extremamente exigente, e isso tudo de maneira orgânica. 
Gurdjieff em seus escritos quase nunca se refere aos conceitos e ideias de forma direta, estes aparecem quase sempre por uma via indireta, na forma de diálogos, histórias e metáforas, impressōes que ele recebeu em alguns dos inúmeros locais pelos quais passou. Quando eventualmente se refere às ideias e conceitos mais diretamente, isto aparece na forma de reconstituiçóes que seus alunos fizeram de suas palavras. Nestes casos há que se considerar que as palavras e as ideias que elas expressam, a forma que elas tomam, está dirigida às necessidades e demandas daquele grupo de pessoas. Com Grotowski parece acontecer algo similar na medida em que a terminologia vai mudando junto com as fases e as pessoas a quem se dirige. É como se houvesse uma intuição que guia e chama, ainda que por caminhos cada vez diversos de experimentação e realização. Para Gurdjieff e Grotowski parece não haver dogmas, mas uma busca intensa e constante.

\section{Essência e Personalidade}

Dois termos que podem ser comparados são essência e personalidade. Para Gurdjieff, assim como para Grotowski, estas palavras designam certos aspectos da constituição do homem que são de natureza oposta e complementar.

As palavras essência e personalidade têm sido empregadas em muitos campos do conhecimento com significados específicos e às vezes muito diversos. Até mesmo dentro de um mesmo campo elas podem assumir nuances diferentes de acordo com a linha a que está filiado o discurso. Por exemplo, a palavra essência está implicada em um debate filosófico que tem pouca relação com o aspecto que designa no trabalho destes pesquisadores. Platão considerava as ideias ou formas como modelos e via-as como essências. Aristóteles usa uma expressão que pode ser traduzida por "[...] o que era antes de ter sido" (Mora, 2001, p. 226) que seria uma substância anterior às qualidades. Os escolásticos medievais desenvolveram intenso debate sobre a questão da essência que tem repercussão na modernidade e na contemporaneidade. Em linhas bastante gerais se poderia dizer que a proposta essencialista busca encontrar e discernir, nas coisas, as propriedades que são essenciais em oposição às que são acidentais. "As propriedades essenciais são as que uma coisa não pode perder sem deixar de existir" (Blackburn, 1997, p. 126). Nessa concepção, um 
homem ocupar um determinado espaço seria um tipo de propriedade essencial, enquanto usar um chapéu seria um tipo de propriedade acidental. A primeira tem um aspecto fixo, ontológico do ser ao qual se refere. A segunda pode variar com a situação de maneira acidental, pode ou não ocorrer. A discussão é longa e complexa, segundo Mora: "[...] as respostas dadas ao problema da essência dependeram em grande parte do aspecto que se tenha sublinhado e, em especial, se foi sublinhado o aspecto lógico (conceitual), ou o aspecto metafísico (real), ou porventura uma combinação de ambos" (Mora, 2001, p. 227). Ainda que se possa encontrar algo em comum no campo semântico, para Gurdjieff e Grotowski as palavras essência e personalidade designam, cada uma, determinada natureza específica do ser humano. Tais conceitos náo estáo relacionados diretamente à filosofia essencialista. Assim como Gurdjieff, Grotowski foi um pesquisador viajante e o seu trabalho está impregnado do contato com tradições antigas ocidentais e não ocidentais. Também é preciso considerar que, em sua formação, Grotowski teve profundo contato com a tradiçáo indiana de tal forma que essa tradiçáo tem sempre, como pano de fundo, certa presença em seu pensamento e ação 7 . Também Gurdjieff desenvolveu sua pesquisa prioritariamente em locais da Ásia que teriam naquele momento, na virada do século XIX para o XX, pouco ou nenhum contato com a tradiçáo filosófica e psicológica do ocidente. Tanto o trabalho de Grotowski quanto o de Gurdjieff, suas terminologias e conceitos, requerem ser lidos a partir de uma ampliação de referências, buscando reconhecer o diálogo que estabelecem com sistemas de pensamentos e filosofias de diversas origens e tradições. Por isso, o interesse em reconhecer proximidades entre as proposiçóes de Grotowski e Gurdjieff. Outras proximidades ainda podem e precisam ser buscadas para reconhecer aspectos do trabalho de Grotowski em sua amplitude.

Referindo-se à essência, Thomas Richards interpreta o pensamento de Grotowski da seguinte maneira:

A que quis se referir Grotowski com a palavra essência? "Essência" pode estar relacionada com organicidade, mas é uma noção diferente. Essência é o que vem de você, o que é seu, o que não foi colocado em você por seus pais, pela educaçáo ou pela sociedade. Normalmente nós podemos encontrar a essência mais em evidência durante a infância. Com o tempo, educação e a formação, entretanto, a pessoa constrói outro aspecto fundamental, que é feito, entre outras coisas, de hábitos físicos e emocionais além de padrões 
de pensamento, de formas aprendidas de relacionar-se com o mundo que são práticas e necessárias no sentido de confrontar a situação pessoal com o "mundo como ele é"; isso é constituído por tudo aquilo que a pessoa incorporou de fora. Porém essa camada de nós mesmos não é necessariamente o que encontramos na essência, e algumas vezes as duas esferas podem ter desejos, gostos, e vontades que são opostas e contraditórias $^{8}$ (Richards, 2008, p. 110).

Talvez pelo fato de perceber que cada um de nós tem um corpo físico, é bastante comum a ideia de que cada um de nós tem um eu estável e constante. Ver que temos hábitos físicos, mentais e emocionais que respondem às situações de maneira automática não é um tipo de observação que aprendemos a fazer de nós mesmos na educação formal ou informal. É raro em nossa sociedade ver e admitir que aquilo que chamamos de indivíduo não é na verdade indivíduo, mas fragmentos, vários eus. Quando muito somos forçados a ver isso pelo conflito que tal situaçáo produz e pelo sofrimento dele decorrente. $\mathrm{E}$ esse sofrimento pode estar no nível do aprendido, nessa camada a que Richards refere-se como outro aspecto fundamental. O conflito entre esse aspecto, a personalidade e a essência é ainda mais insondável, exige um trabalho sobre si profundo e constante. $\mathrm{O}$ interessante na descrição que fazem Grotowski e Richards é que eles apontam para algo mais do que uma diferença de intensidade entre a essência e esse outro aspecto fundamental. Trata-se de uma diferença de qualidade. A essência, mais evidente durante a infância, continua vivente enquanto esse outro aspecto fundamental vai se formando mais intensamente em interaçáo recursiva com o meio, e segue também existindo. A diferença é de natureza, a tal ponto que chegam a ter desejos, gostos e vontades que sáo opostas e contraditórias. O que significa que elas coexistem no tempo e no espaço. Assim, a essência, uma qualidade que se manifesta de forma mais evidente na infância, segue vivente não apenas como memória, mas como uma presença.

A essência: etimologicamente se trata do ser (being), da seridade (be-ing). A essência me interessa porque não tem nada de sociológico. E isso que não é recebido dos outros, aquilo que não vem do exterior, que não é aprendido. Por exemplo, a consciência (no sentido de "the conscience", a consciência moral) é algo que pertence à essência, e que é de todo diferente do código moral que pertence à sociedade. Se tu infringes o código moral, te sentes culpado, é a sociedade a que fala em ti. Porém se fazes um ato contra a consciência, sentes remorso - isto é entre tu e tu mesmo, e não entre tu e a sociedade (Grotowski, 1996, p. 77). 
A afirmação de que a essência não tem nada de sociológico, se por um lado é um choque, por outro abre a possibilidade de um tipo de interação entre os homens, que é anterior ao social e à cultura. Para Grotowski era bem clara a distinção de qualidade entre a essência, que não tem nada de sociológico, e o que é aprendido (e nomeado) em interação com a sociedade. Aqui ele fala de uma consciência moral que é ainda diferente da moralidade como um código, um tipo de contrato, que surge quando o social começa a ter um peso significativo na vida do indivíduo. Para Grotowski, a consciência moral seria ainda anterior, por estar ligada à essência. $\mathrm{O}$ código moral que está radicado na sociedade corresponde à açáo da personalidade, na medida em que esta é constituída por tudo aquilo que a pessoa incorporou de fora. Gurdjieff refere-se a isso que Grotowski denomina the conscience como consciência moral objetiva (Gurdjieff, 2003, p. 252), exatamente por estar radicada na essência e não na personalidade.

Ouspensky, citando uma fala de Gurdjieff:

Lembremos que o homem é constituído de duas partes: essência e personalidade. A essência no homem é o que lhe pertence. A personalidade no homem é o que não lhe pertence. $\mathrm{O}$ que não lhe pertence significa: o que lhe vem de fora, o que aprendeu ou o que reflete; todos os traços de impressốes exteriores deixados em sua memória e nas sensações, todas as palavras e todos os movimentos que lhe foram ensinados, todos os sentimentos criados por imitaçáo, tudo isto é o que não lhe pertence, tudo isso é personalidade (Ouspensky, 1989, p. 188).

A descrição da essência aqui é bem próxima da que Grotowski faz. O que Richards se refere como outro aspecto fundamental, Gurdjieff nomeia personalidade. Grotowski também assume as palavras e a similaridade, e a descriçáo que Richards faz coincide com a de Gurdjieff. Portanto, considero que estas são palavras de trabalho para eles, e designam aspectos que, além de teoria, são vivências práticas coincidentes no seu trabalho, ou seja, elas designam os mesmos eventos.

Alguns pesquisadores/educadores como Montessori, Piaget e Steiner ${ }^{9}$, além das diferenças de abordagem, relataram em sua observação algumas semelhanças com relação aos períodos de formação da criança. Há um primeiro momento em que literalmente a criança absorve o mundo. A individualidade ainda náo é uma entidade no sentido de sentir-se separada do mundo. No entanto, essa vida que absorve o mundo constituirá uma natureza de uma qualidade singu- 
lar, que resulta de literalmente absorver o mundo. Isto é bem distinto do que ocorrerá com a puberdade, quando começa a constituir-se outra natureza que se confronta com o mundo, mas náo é capaz de absorvê-lo. Pelo contrário, separa-se dele e constitui uma segunda individualidade. Para Gurdjieff, a essência inicia sua constituição durante os primeiros anos de vida, antes da constituição da personalidade. Em outra oportunidade ele descreve estes aspectos com os nomes de vida interior ou primeira totalidade para a essência, vida exterior ou segunda totalidade para a personalidade, e de terceira totalidade para a possibilidade de um contato voluntário entre as duas primeiras totalidades (Gurdjieff, 2000, p. 176-178). Para Gurdjieff, em um adulto seguem vivendo essência e personalidade, muitas vezes de maneira conflituosa, como ilustra Richards. O contato entre essas duas naturezas não é algo que possa ocorrer mecanicamente. É necessária uma força, certa condição que viabilize o contato voluntário. Do contato voluntário é que poderia emergir uma qualidade de presença, de atenção e de consciência, a terceira totalidade. Esse processo que medeia o contato entre essência e personalidade, Gurdjieff chama de contemplação.

Contato é uma importante palavra praticada de Grotowski. Segundo Tatiana Motta, ao analisar o termo no léxico grotowskiano, “[...] pode-se dizer que existem várias camadas de compreensão desse conceito, mas que, de forma geral, estar em contato significava estar em relação com" (Lima, 2012, p. 191). Em Grotowski, o contato nasceu de uma necessidade de contrapor a observação identificada de si, que ele costumava referir-se como ator narcisista, à possibilidade de doar-se. O contato, e dele o confronto com o parceiro ou a situaçáo, funcionaria como uma espécie de despertador abrindo passagem para um impulso profundo. Implicaria ao mesmo tempo um contato com o parceiro e consigo, na medida em que suscitaria reaçóes náo automáticas e habituais. Grotowski desenvolveu ainda uma terceira possibilidade, o contato com espaço. Há relatos de como em suas palestras ele demonstrava as açóes físicas em contato com a plateia, seja arrumando o cachimbo frente a uma pergunta ou avaliando na plateia pessoas que concordavam ou não com suas assertivas.

Estas várias camadas do conceito dizem respeito, basicamente, ao objeto do contato e, nesse aspecto, se poderia dialogar com Brook, dizendo que o contato pode ser basicamente em relação a si mesmo, o parceiro e o público ou espaço (Brook, 2010). Essa constataçáo de 
Brook talvez tenha se inspirado em uma fórmula similar a Gurdjieff quando ele apresenta as três linhas de trabalho de uma escola, a primeira linha o trabalho sobre si, a segunda linha o trabalho com os companheiros e a terceira linha o trabalho para o trabalho (ou a escola), ou seja, constituir as condiçóes para que o trabalho siga existindo (Ouspensky, 1995).

Com relação ao trabalho sobre si, o contato passa pelo corpo. Em Grotowski, o corpo assumiu diversos estatutos que iam de um local de impedimento até o seu oposto, o instrumento do milagre. Como local de impedimento, o ator, identificado com o próprio corpo, com as habilidades desenvolvidas, seduzido por elas, cairia no narcisismo, este era o perigo ${ }^{10}$. Para estar livre o ator deveria oferecer-se em uma espécie de sacrifício, confissão ou anulação, que no primeiro momento estava exatamente centrada no corpo, como se ele fosse o impedimento, ou como se através dele se pudesse trabalhar sobre o impedimento, que é um pouco diferente ${ }^{11}$. Nesta outra perspectiva o corpo se transforma em um instrumento de ação, de trabalho sobre si. Nesta linha de trabalho é fundamental o contato com a natureza passiva, a essência. O que Grotowski chama de infantilismo consciente (Grotowski, 2007, p. 44) poderia ser um caminho para este contato, uma vez que na essência é que reside a receptividade que possibilitaria o jogo, e uma qualidade de presença que emerge do contato entre essência e personalidade (contemplação, segundo Gurdjieff).

Aqui o contato com o companheiro começa a ser fundamental. Diríamos que a presença que emerge do contato voluntário entre aspectos da personalidade e da essência, viabiliza, permite o contato com o companheiro. A personalidade, o mundo do aprendido, não é mais um impedimento, mas passa a ser um instrumento a serviço de uma meta comum. Em um grupo musical, por exemplo, é evidente quando esta porta se abre ${ }^{12}$. Neste momento há a circulaçáo de uma energia sutil que une. Para os músicos não importa mais quem produziu tal ou qual som, todos são a música, o som que cada um produz cala no outro, senáo da mesma forma, pelo menos de uma forma muito similar. Passa-se nesta situação um fenômeno que Grotowski nomeou, em algumas situações, como indução.

A partir desse momento, o grupo passa a ser responsável pelas condiçôes necessárias para que o próprio processo ocorra, o contato com o espaço revela-se fundamental. Se poderia dizer que a ideia de espaço permite várias abordagens. Poderia ser o público, poderia ser 
o espaço físico, mas poderiam ser também as condiçóes para que a produção seja sustentada, tanto fisicamente, no que diz respeito ao visivel, quanto náo fisicamente, no que diz respeito ao invisivel. Brook indiretamente coloca a questáo do contato quando trata de um mundo invisivel que é preciso tornar visivel. Para ele, o invisível é ainda mais profundo que as formas conhecidas e aceitas da psicologia, são fontes de energia extremamente poderosas e estão no âmbito do que ele chama de sagrado.

Nesses campos de energia quase desconhecidos existem impulsos que nos guiam para "qualidade". Todos os impulsos humanos direcionados para o que chamamos, de modo impreciso e canhestro, de "qualidade" provêm de uma fonte cuja verdadeira natureza é totalmente desconhecida, mas que somos perfeitamente capazes de reconhecer quando se manifesta em nós ou nos outros. Ela não se comunica por sons ou ruídos, mas através do silêncio. É o que chamamos - já que temos que usar palavras - "de sagrado" (Brook, 2010, p. 49).

A qualidade, com a acepção que lhe dá Brook, parece estar muito próxima do que Grotowski nomeava como awareness. Brook e Grotowski estiveram muito próximos, sendo que Brook cunhou o nome de Arte como Veículo para a última fase de Grotowski. Também Brook está ligado ao trabalho de Gurdjieff, sendo hoje um dos principais responsáveis por essa tradiçáo no mundo e, portanto, provavelmente foi uma das pontes entre Grotowski e Gurdjieff.

\section{Retirar Impedimentos}

\section{Segundo Grotowski}

[...] o material e as técnicas que apareciam espontaneamente durante a preparação do espetáculo eram muito mais promissores do que a aplicaçáo de pressupostos teóricos que eram na realidade muito mais função da minha personalidade que do meu intelecto (Grotowski, 2007, p. 107).

Esta declaração mostra como em Grotowski operava a crítica no confronto com os experimentos durante os ensaios e no trabalho com os atores, reconhecendo nos pressupostos teóricos uma instância que atuava como uma manifestação da personalidade, de maneira pouco funcional e dura. Esta distinção entre personalidade e intelecto é instigadora. Na personalidade está o universo de açóes aprendidas que, agindo por si, o fazem como reação mecânica a estímulos externos, que assumem uma determinada forma. Grotowski, para referir-se 
a estes aspectos quando eles tornavam-se um impedimento à ação, solicitava que os atores encontrassem nomes ou expressóes para eles, que eram as fórmulas da personalidade. A personalidade como entidade não é em si um impedimento, constitui-se uma natureza do homem na qual está tudo o que foi aprendido, todo o ofício que é fruto de um treinamento, por exemplo. Quando nela se cristalizam atitudes e reaçóes pré-concebidas, que reagem mecanicamente nas interaçóes com o mundo, estas atitudes tornam-se um impedimento para um contato com a essência e a constituição de uma presença. Grotowski e Gurdjieff usavam uma mesma palavra para se referir a este estado de impedimento, identificação (Ouspensky, 1989, p. 251). Em Gurdjieff, o trabalho sobre si é que poderia levar a um estado de não identificação. Neste trabalho sobre si o relaxamento físico tem um papel central, não para estar apartado do mundo em um tipo de isolamento, mas, pelo contrário, para permitir que as impressóes do mundo possam entrar. Isto corresponde ao princípio da via negativa de retirar os impedimentos e seria como colocar-se diante destas atitudes e posturas cristalizadas na personalidade, e esta posição reduziria a força de impedimento que tais atitudes e posturas têm sobre o fluxo da atenção, o que em Gurdjieff corresponderia a aproximar-se a um estado de náo identificaçáo. Pode-se dizer que o impedimento e/ou as resistências implicam uma horizontalidade, que manteriam a atenção presa a um nível associativo mecânico. Voltando à citação, a aplicaçáo de pressupostos teóricos a partir da personalidade levaria a uma ação horizontal de inércia e mecanicidade. $\mathrm{O}$ termo intelecto aqui sugere um pensar de outra qualidade. Para poder se contrapor às formas $\mathrm{da}$ personalidade, à mecanicidade de seus processos, o intelecto, a que se refere Grotowski, deve ser algo mais luminoso, diferente das formas de pensamento habituais quando limitadas pela identificação, mas de um pensar ativo e livre. Em outras passagens, ele se refere a awareness.

Poder-se-ia dizer também que awareness está relacionado com o intelecto, porém neste caso se trata de outro intelecto. Nele há um encontro com o coração, um encontro na esfera da alma, da emoçáo, porém desta vez distinto da nossa mescla de projeçóes, repulsões e afetos; pertence à mesma esfera, porém muito mais elevada, e nesse ponto não existe diferença perceptível entre essa alta "psique" e este alto "intelecto"; os dois aspectos estão entáo muito vinculados e são quase idênticos (Grotowski, 1997, p. 120). 
Contrapondo-se à horizontalidade, ele aponta a necessidade de uma verticalidade que daria suporte à açáo. Para Grotowski, o alinhamento entre o corpo, o coração e a cabeça é fundamental para a verticalidade que surge como um processo contingente e necessário à atividade criadora e à busca de uma alta conexão. Grotowski utiliza a imagem de um elevador primitivo, com o qual o atuante se eleva rumo a uma qualidade energética mais sutil para depois regressar ao nível mais denso trazendo consigo tal qualidade.

\section{O Ofício a Serviço do Contato}

Como as explicaçóes científicas, a arte precisa ter categorias compartilhadas e validadas em uma determinada comunidade. A validação das categorias é assunto da cultura, mas para haver descriçóes é preciso alguém que descreva. A descrição compartilhada culturalmente, o seu funcionamento, poderia ocorrer mecanicamente, uma vez realizado o caminho de sua constituiçáo. Isso poderia ser algo social, mas não uma presença que se revela no indivíduo. Em tal presença, uma qualidade sutil poderia revelar-se na medida em que as descriçôes, que a personalidade faz, estáo a serviço do contato com a essência, ainda que esta se mantenha passiva e naturalmente silenciosa. A presença, nessa acepção, refere-se a uma emergência que resultaria desse contato voluntário, que Gurdjieff chama de contemplaçáo.

Portanto, na emergência de uma presença, se poderia considerar a possibilidade de que as impressóes que nos chegam possam tocar a essência, mesmo que as descriçóes que delas se faça não sejam plenamente compartilhadas. De fato, pesquisadores como Grotowski, Richards, Brook e Barba ao se lançarem em uma pesquisa de teatro intercultural, envolvendo atores de diferentes nacionalidades e culturas, intuíram essa possibilidade. A qualidade que é compartilhada é a presença, ainda que as descriçóes (categorizaçóes) não sejam coincidentes.

Uma possibilidade seria lançar um olhar para além das diferenças de culturas, de tal maneira que o aspecto que chamamos de personalidade e que inclui o ofício, tornar-se-ia não um impedimento, mas um instrumento de contato com a essência. Tal impedimento é comum e especialmente acentuado na vida dos indivíduos na contemporaneidade ${ }^{13}$, tendo em vista a ênfase que a educaçáo e as condiçóes 
de vida neste momento colocam no desenvolvimento da personalidade e em sua desconexáo com a essência, o saber em detrimento do ser.

Retirar impedimentos era para Grotowski um importante tema no trabalho sobre si do ator, e a base do que ele chamava a via negativa. Para viabilizar tal ação, uma possibilidade seria desenvolver um ofício consistente só para colocá-lo a serviço do contato com a essência. É a qualidade gerada pelo contato que toca e une. Grotowski enfatizou a necessidade do ofício em diversas oportunidades, depois de ter feito inúmeros experimentos com seus atores, assim como com mestres de tradiçóes diversas, no Teatro das Fontes.

Gurdjieff e Grotowski desenvolveram uma investigação que tem conexấo com conhecimentos antigos que parecem muito necessários à contemporaneidade, pois correspondem a perguntas fundamentais que seguem abertas, mesmo com todo desenvolvimento científico e tecnológico de nosso tempo. O diálogo entre eles, ainda que náo tenha ocorrido de fato, poderia ser desenvolvido por aqueles que assumem seu legado, como fonte de aprofundamento e vivificação. 


\section{Notas}

${ }^{1}$ Além do interesse que desenvolveu em áreas correlatas como a psicologia, a filosofia e a antropologia.

${ }^{2}$ Não há um registro preciso do nascimento de Gurdjieff na cidade de Alexandropol, então império russo, atualmente Gyumri na Rússia. Costuma-se aceitar o dia 14 de janeiro de 1866. Em 1922 se estabelece em Fontainebleau na França e depois em Paris, onde faleceu em 29 de outubro de 1949.

${ }^{3}$ Atualmente o Instituto está presente em diversos países.

${ }^{4}$ Texto original: [...] desde el momento en que empecé a leer sobre el trabajo de Gurdjieff, las comparaciones prácticas y las conclusiones no solamente debían corroborarse sino que debían además tocarme, es evidente. Me resultaría difícil analizar: ¿qué detalles, qué elementos? Porque también puede resultar peligroso preguntarse: ¿de dónde viene un elemento, y de dónde viene otro? Lo importante no es que vengan de alguna parte sino que funcionen. ¿Está claro el criterio? Eso quiere decir: hay un elemento que funciona y se corrobora aquí e allá. En el caso de Gurdjieff, el impacto es de algo a la vez muy antiguo y contemporáneo. Son fuertes a la vez la tradición e la búsqueda, y al mismo tiempo allí está la manera de plantear ciertas preguntas fundamentales.

5 Texto original: Cuando tuve a mano ciertos materiales, comprobé en efecto una utilización similar de ciertos términos como por ejemplo "mecanicidad", "asociaciones". En otras partes, los términos difieren pero sin embargo están la "máscara social", la "personalidad"...y uno podría seguir y seguir! Lo que probablemente sea más importante mencionar es la complejidad de la naturaleza humana, que abarca el cuerpo, y la interioridad - quizás con algo más que realizar o hacer - hacia lo que llamo hoy "la verticalidad" (aspas do autor).

${ }^{6}$ Em seu livro Fragmentos de um Ensinamento Desconhecido, Ouspensky faz muitas citaçóes de falas de Gurdjieff. O texto foi revisado pelo próprio Gurdjieff e autorizado, portanto considero que as referidas citaçóes têm autenticidade no seu conteúdo.

${ }^{7}$ Segundo Flazen, ao comentar o seguinte texto de Grotowski: "superar ou desmentir o eu 'aprendido", pergunta: "[...] existe um eu náo aprendido, além do jogo social e dos condicionamentos históricos?" E segue "[...] o futuro autor de Performer já muito antes da gênese de Opole tinha praticado ioga e conhecia muito bem a filosofia indiana, portanto provavelmente sabia o que dizia" (Flaszen, 2007, p. 26-27).

8 Texto original: What did Grotowski refer to with the world 'essence'? 'Essence' can be related to organicity, but it's a different notion. Essence is what comes from you, what is ours, what is not put in you by your parents, by education, or society. Normally we can find essence more in evidence during the youth. With time, education, and upbringing, however, a person constructs another fundamental aspect, which is made up, among other things, of learned physical and emotional habits and thought patterns, of learned ways of relating with the world that are useful and necessary in order to confront one's personal situation in 'the world as it is;' it's made up of all that a person has incorporated from outside. But this layer of ourselves is not necessarily a reflection of what we find in essence, and sometimes the two spheres can have desires, tastes, and wishes that are opposed and contradictory. 
${ }^{9}$ Cito esses pesquisadores/educadores considerando que atualmente são sistemas bastante influentes no ensino em diversos locais, ainda que se faça alguma crítica a determinados aspectos aqui e acolá.

${ }^{10} \mathrm{Na}$ abordagem de Gurdjieff, se poderia dizer que se trata de um contato com a personalidade e só com ela, com o mundo do aprendido, com o que não é seu.

${ }^{11} \mathrm{E}$ foi nessa direção que evoluiu a questão da relação com o corpo no trabalho de Grotowski, passando de um impedimento para uma espécie de pista para alçar voos maiores.

${ }^{12}$ Em muitos momentos aparecem neste trabalho citaçóes e exemplos do funcionamento de ideias e conceitos com referência à atividade musical. Por um lado, trata-se de uma atividade que envolve e, portanto, compartilha processos relativos à performance. Por outro, sendo música o meu campo de atuação, é de onde posso colher experiências que ilustrem na prática as ideias colocadas.

${ }^{13}$ Talvez tenha sido sempre assim para os homens, considerando as referências a esta situação que aparecem em algumas tradiçóes, como o véu de maia para o budismo, ou ainda o conceito de identificação em Gurdjieff e Grotowski. No entanto, é preciso pontuar que essa situação está exacerbada em nossos dias. É evidente a necessidade de uma espécie de ecologia do ser.

\section{Referências}

BLACKBURN, Simon. Dicionário Oxford de Filosofia. Rio de Janeiro: Jorge Zahar Editor, 1997.

BROOK, Peter. A Porta Aberta. Rio de Janeiro: Civilização Brasileira, 2010.

GROTOWSKI, Jerzy. El Performer. Máscara, Cuaderno Iberoamericano de Reflexión sobre Escenología, México, ano 3, n. 11-12, out. 1992, reed. out. 1996. Espacio editorial del teatro iberoamericano (EETI).

GROTOWSKI, Jerzy. Era como um Volcán. In: PANAFIEU, Bruno. Gurdjieff, Textos Compilados. Caracas: Editora Ganesha, 1997. P. 117 a 151.

GROTOWSKI, Jerzy. Farsa - Misteriun. In: FLASZEN, Ludwik; POLLASTRELLI, Carla. O Teatro Laboratório de Jerzy Grotowski 1959-1969. São Paulo: Editora Perspectiva, 2007. P. 40 a 47.

GROTOWSKI, Jerzy. Em Busca de um Teatro Pobre. In: FLASZEN, Ludwik; POLLASTRELLI, Carla. O Teatro Laboratório de Jerzy Grotowski 1959-1969. São Paulo: Editora Perspectiva, 2007. P. 105 a 118.

GURDJIEFF, George Ivanovitch. A Vida só é Real quando “Eu Sou”. São Paulo: Horus Editora, 2000.

GURDJIEFF, George Ivanovitch. Relatos de Belzebu a seu Neto: crítica objetivamente imparcial da vida dos homens. Sáo Paulo: Horus Editora, 2003.

LIMA, Tatiana Motta. Palavras Praticadas: o percurso artístico de Jerzy Grotowski, 1959-1974. São Paulo: Perspectiva, 2012. 
MATURANA, Humberto. Emoçóes e Linguagem na Educaçáo e na Política. Belo Horizonte: Editora UFMG, 2005.

MORA, José Ferrer. Dicionário de Filosofia. São Paulo: editora Martins Fontes, 2001.

OUSPENSKY, Piotr Demianovich. Fragmentos de um Ensinamento Desconhecido: em busca do milagroso. São Paulo: editora Pensamento, 1989.

OUSPENSKY, Piotr Demianovich. O Quarto Caminho. São Paulo: editora Pensamento, 1995.

RICHARDS, Thomas. Heart of Practice: Within the Workcenter of Jerzy Grotowski and Thomas Richards. London and New York: Routledge, 2008.

Mauro Rodrigues é graduado em flauta pela Escola de Música da Universidade Federal de Minas Gerais (UFMG), possui mestrado em musicologia pelo Conservatório Brasileiro de Música (RJ) e doutorado em Artes pela UFMG. Atualmente é professor na Escola de Música da UFMG e atua como produtor, compositor, arranjador e instrumentista.

E-mail:maurorod@uai.com.br

Recebido em 25 de setembro de 2012 Aprovado em 05 de novembro de 2012 